\title{
Global Unique Device Identification Database Submission
}

National Cancer Institute

\section{Source}

National Cancer Institute. Global Unique Device Identification Database Submission. NCI

Thesaurus. Code C101716.

The submission of a global unique device identification record. 